\title{
A Correlation Analysis on the Depth and Breadth of ESL Learners' Vocabulary Knowledge and Their Overall Linguistic Competence
}

\author{
Zhaogang Wang \\ School of International Business Communication, Dongbei University of Finance and Economics, Dalian, China
}

\begin{abstract}
The breadth and depth of ESL learners' vocabulary knowledge and their comprehensive linguistic competence are not well studied in current literatures on vocabulary studies. This paper explores the creditability of depth and breadth of ESL learners' vocabulary knowledge as an indicator of their overall linguistic competence and the correlation between depth and breadth of ESL learners' vocabulary knowledge. The results show that both the depth and breadth of ESL learners' vocabulary knowledge can effectively be representative of their linguistic competence, of which the depth of ESL learners' vocabulary knowledge is better than the breadth of their vocabulary knowledge as an indicator of their overall linguistic competence. In general, the breadth of ESL learners' vocabulary knowledge is highly positively correlated with the depth of their vocabulary knowledge but the development of depth of vocabulary knowledge still lags behind the development of breadth of vocabulary knowledge.
\end{abstract}

Index Terms - breadth of ESL learners' vocabulary knowledge, depth of ESL learners' vocabulary knowledge, comprehensive linguistic competence, correlation analysis, SPSS

\section{INTRODUCTION}

The development of ESL learners' vocabulary knowledge is key to the growth of their overall linguistic competence. Many ESL learners spend most of their English learning time expanding their vocabulary knowledge because they believe a large vocabulary is the solid foundation for other language skills. What does it mean to know an English word? Many lexicologists (Chappelle, 1998; Wesche \& Paribakht, 1996; Qian, 1999, 2002; Qian \& Schedle, 2004) claim there are at least two dimensions to ESL learners' vocabulary knowledge: breadth and depth. The breadth of L2 learners' vocabulary knowledge is the total quantity of their reading vocabulary and the depth of L2 learners' vocabulary knowledge means their understanding of synonyms, multiple explanations and collocations of the same word. What impacts do ESL learners' depth and breadth of vocabulary knowledge have on their overall linguistic competence? What is the correlation between depth and breadth of ESL learners' vocabulary knowledge? This paper attempts to answer these questions through an experiment with some common vocabulary tests.

\section{MEthodology}

\section{A. Subjects of Vocabulary Tests}

The subjects of vocabulary tests were five classes of non-English majors of 2012 grade in a Chinese university: statistics majors (45 students), economics majors (47 students), engineering majors (41 students), journalism majors (43 students), law majors (34 students), of which 16 students took the tests once and 26 students did not finish the tests as required. Therefore we have got 168 effective test papers.

\section{B. Test Instruments}

Test instrument of breadth of ESL learners' vocabulary knowledge: we used a test paper designed by Schmitt et al. $(1997,2001,2002)$ on the basis of a vocabulary test by Nation $(1983,1990)$. Our test paper includes five parts: 2000 words, 3000 words, 5000 words, 10000 words and academic vocabulary. The 2000-word and 3000-word parts represent the most frequently used words, and the 5000-word part represents medium-frequency words and the 10000-word part represents low-frequency words. Academic vocabulary is taken from Coxhead (2000) which has 570 words covering the most frequently and widely used words in 28 disciplines. Every part has 10 questions and each question tests 6 target words and three meanings. In each question test takers were asked to choose 3 words from 6 words matching the corresponding explanations. An example is given as follows:
a. company
b. watch f part of a house
c. pen e animal with four legs
d. shirt c something used for writing
e. $\operatorname{dog}$ 
f. window

The English explanations in each test question used the most frequently used 2000 words in order to prevent the negative impacts of subjects' misunderstanding of English explanations on the effectiveness of the experiment. In addition, the test minimized the possibility of subjects' blind guess in the experiment. Test takers get one point if they answer one question correctly and the total score for this part is 120 points $(3 * 10 * 4=120)$

Test instrument for depth of ESL learners' vocabulary knowledge: Word Associate Test (reliability 0.93) designed by Read (1995) is used. The answers for 8 questions in the original test are problematic and the target words of 4 questions are beyond the subjects' proficiency level, therefore these parts were replaced by questions designed by Qian $\&$ Schedle (2004). This test includes 40 target words. Each question has two boxes and four correct choices which test paradigmatic and syntagmatic relations of target words respectively. An example "sound" is given as follows:

\begin{tabular}{|l|l|}
\hline logical healthy bold solid & snow temperature sleep dance \\
\hline
\end{tabular}

"Logical", "healthy" and "solid" in the left box are synonyms of "sound" and "sleep" in the right box usually collocates with "sound". The distribution of correct choices is random so as to reduce the possibility of subjects' blind guesses. Test takers get one point with one correct choice so the total score for this test is 160 points $(4 * 40=160)$

Test instruments for comprehensive linguistic competence: PETS (public English test system) test Band 3 is used to test the comprehensive linguistic competence. Because the PETS test is not designed for four-year college students but for the general public and students of vocational schools, most subjects in this experiment have little chance to take the test and the results of the experiment also show that the subjects did not take the test before the experiment. Students who pass the PETS Band 3 have English proficiency of second-year college students of non-English majors. Therefore this test paper is appropriate for students in this experiment. This test has four parts: listening $(1 * 25=25$ points); cloze $(1 * 20=20$ points); and reading comprehension $(2 * 20=40$ points); writing (15 points). The total score of the test is 100 points. Listening, cloze and reading are all multiple choice questions. Writing is based on a picture. 2 teachers credit the writing part individually on the basis of students' accuracy, fluency, coherence and clarity. If the two teachers cannot agree with each other on one paper, they would have to ask another teacher to credit the same paper again until they could reach an agreement on the score of the paper.

\section{Data Collection and Analyses}

Because all subjects were asked to take the tests without prior notice, some subjects were absent in some tests. Three tests were conducted in two experiments. The first experiment tested subjects' breadth and depth of vocabulary knowledge. In order to carry out the experiment properly, we spent 10 minutes demonstrating and training students how to take the tests which lasted for 100 minutes. The second experiment tested students' comprehensive linguistic competence which also took 100 minutes. Both experiments were done in normal class hours by English teachers under our supervision. There was a three-day interval between the two experiments. All test results were keyed into computers and analyzed with SPSS.

\section{RESULTS AND DISCUSSIONS}

Table 1 lists the average score, standard deviation, score range and reliability of the tests on breadth and depth of vocabulary knowledge and comprehensive linguistic competence. The results show that the score distributions of all tests are relatively reasonable and the reliability is also fairly high.

TABLE I

DESCRIPTIVE STATISTICS AND RELIABILITY OF THE TEST RESULTS ON BREADTH AND DESCRIPTIVE STATISTICS AND RELIABILITY OF THE TEST RESULTS ON BREADTH AND
DEPTH OF VOCABULARY KNOWLEDGE AND OVERALL LINGUISTIC COMPETENCE $(\mathrm{N}=168)$

\begin{tabular}{llllll}
\multicolumn{2}{c}{ DEPTH OF VOCABULARY KNOWLEDGE AND OVERALL LINGUISTIC COMPETENCE (N=168) } \\
\hline Variable & Total score & $\begin{array}{l}\text { Average } \\
\text { score }\end{array}$ & $\begin{array}{l}\text { Standard } \\
\text { deviation }\end{array}$ & Score range & $\begin{array}{l}\text { Reliability } \\
\text { (split half) }\end{array}$ \\
\hline breadth of vocabulary knowledge & 120 & 77.33 & 15.76 & $40-115$ & 0.759 \\
\hline $\begin{array}{l}\text { depth of vocabulary knowledge } \\
\text { comprehensive linguistic }\end{array}$ & 160 & 108.56 & 13.87 & $48-133$ & 0.729 \\
competence & 100 & 57.60 & 9.36 & $26-85$ & 0.701 \\
\hline listening & & & & & \\
\hline cloze & 25 & 11.57 & 3.03 & $3-19$ & 0.729 \\
\hline reading & 20 & 10.39 & 2.78 & $2-16$ & 0.785 \\
\hline writing & 40 & 26.89 & 4.94 & $10-38$ & 0.759 \\
\hline
\end{tabular}

\section{A. Breadth and Depth of L2 Learners' Vocabulary Knowledge and Linguistic Competence}

In order to study the impacts of breadth of L2 learners' vocabulary knowledge on their comprehensive linguistic competence and specific language skills, a linear regression model is built with the breadth of vocabulary knowledge as the independent variable and comprehensive linguistic competence as well as specific language skills as the dependent variable. Table 2 shows that $8.6 \%$ of listening scores, $27.1 \%$ of cloze scores, $28.3 \%$ of reading scores and $31.9 \%$ of writing scores can be attributed to the effects of breadth of vocabulary knowledge. In general, breadth of ESL learners' 
vocabulary knowledge can be used to test their comprehensive linguistic competence which shows that ESL learners could improve their overall language skills through an expansion of the breadth of vocabulary knowledge.

TABLE II

THE IMPACTS OF BREADTH OF VOCABULARY KNOWLEDGE ON COMPREHENSIVE LINGUISTIC COMPETENCE AND ALL LANGUAGE SKILLS.

\begin{tabular}{|c|c|c|c|c|c|}
\hline Model & B & Beta & $\mathrm{t}$ & $p$ & Remarks \\
\hline $\begin{array}{l}\text { Constant } \\
\text { Breadth of vocabulary } \\
\text { knowledge }\end{array}$ & $\begin{array}{l}28.913 \\
0.371\end{array}$ & 0.624 & $\begin{array}{l}10.176 \\
10.300\end{array}$ & $\begin{array}{l}.000 \\
.000\end{array}$ & $\begin{array}{l}\text { Dependent variable: overall linguistic } \\
\text { competence } \\
\mathrm{R}^{2}=.390 \mathrm{~F}=106.086 \mathrm{p}=.000\end{array}$ \\
\hline $\begin{array}{l}\text { Constant } \\
\text { Breadth of vocabulary } \\
\text { knowledge }\end{array}$ & $\begin{array}{l}7.215 \\
0.056\end{array}$ & 0.293 & $\begin{array}{l}6.406 \\
3.941\end{array}$ & $\begin{array}{l}.000 \\
.000\end{array}$ & $\begin{array}{l}\text { Dependent variable: listening } \\
\mathrm{R}^{2}=.086 \mathrm{~F}=15.534 \mathrm{p}=.000\end{array}$ \\
\hline $\begin{array}{l}\text { Constant } \\
\text { Breadth of vocabulary } \\
\text { knowledge }\end{array}$ & $\begin{array}{l}3.292 \\
0.092\end{array}$ & 0.521 & $\begin{array}{l}3.568 \\
7.855\end{array}$ & $\begin{array}{l}.000 \\
.000\end{array}$ & $\begin{array}{l}\text { Dependent variable: cloze } \\
\mathrm{R}^{2}=.271 \mathrm{~F}=61.701 \mathrm{p}=.000\end{array}$ \\
\hline $\begin{array}{l}\text { Constant } \\
\text { Breadth of vocabulary } \\
\text { knowledge }\end{array}$ & $\begin{array}{l}13.985 \\
0.169\end{array}$ & 0.532 & $\begin{array}{l}8.599 \\
8.099\end{array}$ & $\begin{array}{l}.000 \\
.000\end{array}$ & $\begin{array}{l}\text { Dependent variable: reading } \\
\mathrm{R}^{2}=.283 \mathrm{~F}=65.594 \mathrm{p}=.000\end{array}$ \\
\hline $\begin{array}{l}\text { Constant } \\
\text { Breadth of vocabulary } \\
\text { knowledge }\end{array}$ & $\begin{array}{l}4.421 \\
0.056\end{array}$ & 0.565 & $\begin{array}{l}8.837 \\
8.811\end{array}$ & $\begin{array}{l}.000 \\
.000\end{array}$ & $\begin{array}{l}\text { Dependent variable: writing } \\
\mathrm{R}^{2}=.319 \mathrm{~F}=77.642 \mathrm{P}=.000\end{array}$ \\
\hline
\end{tabular}

The experiment confirms that breadth of ESL learners' vocabulary knowledge is highly correlated with their comprehensive linguistic competence $\left(r \geq 0.50, R^{2} \geq 0.25\right)$. The results of regression show that breadth of vocabulary knowledge cannot account for the changes of listening test scores $\left(\mathrm{R}^{2}=.086\right)$. This is mainly because factors like learners' knowledge on pronunciation, their understanding of background information, their listening strategies and their mental state during the test process all have greater impacts on their listening scores than their breadth of vocabulary knowledge.

In order to study the impacts of vocabulary knowledge (both breadth and depth) and the extra impacts of depth of vocabulary knowledge on comprehensive linguistic competence and specific language skills, we use the following steps to process the data collected. First of all, the dependent variable of multivariable regression---comprehensive linguistic competence and specific language skills---is determined; secondly, forced entry is used to process the first independent variable---breadth of ESL learners' vocabulary knowledge, and it is also used to process the second independent variable---depth of vocabulary knowledge, on the basis of which the change of $\mathrm{R}^{2}$ means the extra impacts of the second independent variable on dependent variable; finally stepwise method is used to remove the disqualified independent variable, i.e. those independent variables that have no significant impact on dependent variable.

TABLE III

MULTIVARIABLE REGRESSION WITH BREADTH AND DEPTH OF VOCABULARY KNOWLEDGE AS INDEPENDENT VARIABLE AND COMPREHENSIVE LINGUISTIC COMPETENCE AS DEPENDENT VARIABLE $(\mathrm{N}=168)$

\begin{tabular}{lllll}
\hline Steps & Procedures & Independent variables & $\mathbf{R}^{2}$ & $\mathbf{R}^{2}$ changes \\
\hline $\mathbf{1}$ & Forced entry & Breadth of vocabulary knowledge & $.390^{*}$ & $.494^{*}$ \\
\hline $\mathbf{2}$ & Forced entry & Depth of vocabulary knowledge & $.494^{*}$ & $.104^{*}$ \\
\hline $\mathbf{3}$ & Stepwise & Breadth/depth of vocabulary knowledge & \\
\hline
\end{tabular}

Table 3 shows that when breadth of vocabulary knowledge is included in the regression model, $\mathrm{R}^{2}$ is .390 , i.e. $39 \%$ of the change in comprehensive linguistic competence can be explained by breadth of vocabulary knowledge; when depth of vocabulary knowledge is included in the regression model, $\mathrm{R}^{2}$ increases from .390 to .494 , which means depth of vocabulary knowledge has $10.4 \%$ of extra impacts on comprehensive linguistic competence. $49.4 \%$ of comprehensive linguistic competence can be attributed to the combination of breadth and depth of vocabulary knowledge. Stepwise method shows that the impacts of breadth and depth of vocabulary knowledge on comprehensive linguistic competence have reached significance level, i.e. both factors can effectively predict one's comprehensive linguistic competence.

Using the same steps, a multivariable regression model is built with breadth and depth of vocabulary knowledge as independent variables and specific language skills as the dependent variable. The results of analyses are listed in Tables 4 to 7 .

TABLE IV

MULTIVARIABLE REGRESSION WITH BREADTH AND DEPTH OF VOCABULARY KNOWLEDGE AS INDEPENDENT VARIABLE AND LISTENING SCORES AS DEPENDENT VARIABLE $(\mathrm{N}=168)$

\begin{tabular}{lllll} 
& & VARIABLE AND LISTENING SCORES AS DEPENDENT VARIABLE (N=168) & $\mathbf{R}^{\mathbf{2}}$ & $\mathbf{R}^{\mathbf{2}}$ changes \\
\hline $\mathbf{S t e p s}$ & Procedures & Independent variables & $.086^{*}$ & $.135^{*}$ \\
\hline $\mathbf{2}$ & Forced entry & Breadth of vocabulary knowledge & $.049^{*}$ \\
\hline $\mathbf{3}$ & Forced entry & Depth of vocabulary knowledge & $.135^{*}$ & \\
\hline
\end{tabular}


TABLE V

MULTIVARIABLE REGRESSION WITH BREADTH AND DEPTH OF VOCABULARY KNOWLEDGE AS INDEPENDENT VARIABLE AND CLOZE SCORES AS DEPENDENT VARIABLE $(\mathrm{N}=168)$

\begin{tabular}{lllll}
\hline Steps & Procedures & Independent variables & $\mathbf{R}^{2}$ & $.271^{*}$ \\
\hline $\mathbf{1}$ & Forced entry & Breadth of vocabulary knowledge & $.351^{*}$ & $.080^{*}$ \\
\hline $\mathbf{2}$ & Forced entry & Depth of vocabulary knowledge & $.351^{*}$ & \\
\hline $\mathbf{3}$ & Stepwise & Breadth/depth of vocabulary knowledge & \\
\hline
\end{tabular}

TABLE VI

MULTIVARIABLE REGRESSION WITH BREADTH AND DEPTH OF VOCABULARY KNOWLEDGE AS INDEPENDENT VARIABLE AND READING SCORE AS DEPENDENT VARIABLE $(\mathrm{N}=168)$

\begin{tabular}{lllll}
\hline Steps & Procedures & Independent variables & $\mathbf{R}^{2}$ & $.283^{*}$ \\
\hline $\mathbf{1}$ & Forced entry & Breadth of vocabulary knowledge & $.323^{*}$ & $.040^{*}$ \\
\hline $\mathbf{2}$ & Forced entry & Depth of vocabulary knowledge & $.323^{*}$ & \\
\hline $\mathbf{3}$ & Stepwise & Breadth/depth of vocabulary knowledge & & \\
\hline
\end{tabular}

TABLE VII

MULTIVARIABLE REGRESSION WITH BREADTH AND DEPTH OF VOCABULARY KNOWLEDGE AS INDEPENDENT VARIABLE AND WRITING SCORE AS DEPENDENT VARIABLE $(\mathrm{N}=168)$

\begin{tabular}{|c|c|c|c|c|}
\hline Steps & Procedures & Independent variables & $\mathbf{R}^{2}$ & $\mathbf{R}^{2}$ changes \\
\hline 1 & Forced entry & Breadth of vocabulary knowledge & $.319 *$ & \\
\hline 2 & Forced entry & Depth of vocabulary knowledge & $.453 *$ & $.134 *$ \\
\hline 3 & Stepwise & Breadth/depth of vocabulary knowledge & $.453 *$ & \\
\hline
\end{tabular}

Table 4 shows that depth of vocabulary knowledge beyond breadth of vocabulary knowledge can increase ESL learners' listening score by $4.9 \%$. The combination of breadth and depth of vocabulary knowledge can increase listening scores by $13.5 \%$. Table 5 shows that depth of vocabulary knowledge can increase cloze scores by $8.0 \%$ on the basis of breadth of vocabulary knowledge, and breadth and depth of vocabulary knowledge can increase cloze scores by $35.1 \%$. Table 6 shows that depth of vocabulary knowledge increases reading scores by $4.0 \%$ on the basis of breadth of vocabulary knowledge, and the depth and breadth of vocabulary knowledge together can predict $32.3 \%$ of change in reading scores. Table 7 shows that depth of vocabulary knowledge contributes to writing scores by $13.4 \%$ on the basis of breadth of vocabulary knowledge, and the depth and breadth of vocabulary knowledge can predict $45.3 \%$ of change in writing score. Stepwise method shows that both depth and breadth of vocabulary knowledge can predict effectively the four language skills of listening, speaking, reading and writing. Different from previous models, depth of vocabulary knowledge is put before breadth of vocabulary knowledge in the linear regression process. The results of analyses are listed in Table 8, 9 and 10.

By observing the change of $\mathrm{R}^{2}$, we have found that depth of vocabulary knowledge makes more contributions to the improvement of L2 learners' comprehensive linguistic competence, cloze and writing. In order to confirm the advantages of depth of vocabulary knowledge, we rebuilt three multivariable regression models with depth and breadth of vocabulary knowledge as independent variables and comprehensive linguistic competence, cloze and writing as dependent variables.

TABLE VIII

MULTIVARIABLE REGRESSION WITH DEPTH AND BREADTH OF VOCABULARY KNOWLEDGE AS INDEPENDENT VARIABLES AND COMPREHENSIVE LINGUISTIC COMPETENCE AS DEPENDENT VARIABLE $(\mathrm{N}=168)$

\begin{tabular}{lllll}
\hline Steps & Procedures & Independent variables & $\mathbf{R}^{2}$ & $\mathbf{R}^{2}$ changes \\
\hline $\mathbf{1}$ & Forced entry & Depth of vocabulary knowledge & $.423^{*}$ & $.070^{*}$ \\
\hline $\mathbf{2}$ & Forced entry & Breadth of vocabulary knowledge & $.494^{*}$ &. \\
\hline
\end{tabular}

TABLE IX

MULTIVARIABLE REGRESSION WITH DEPTH AND BREADTH OF VOCABULARY KNOWLEDGE AS INDEPENDENT VARIABLES AND CLOZE SCORES AS DEPENDENT VARIABLE $(\mathrm{N}=168)$

\begin{tabular}{lllll}
\hline Steps & Procedures & Independent variables & $\mathbf{R}^{2}$ & $.305^{*}$ \\
\hline $\mathbf{1}$ & Forced entry & Depth of vocabulary knowledge & $.351^{*}$ & $.046^{*}$ \\
\hline $\mathbf{2}$ & Forced entry & Breadth of vocabulary knowledge & $\mathbf{R}^{2}$ changes \\
\hline
\end{tabular}

TABLE X

MULTIVARIABLE REGRESSION WITH DEPTH AND BREADTH OF VOCABULARY KNOWLEDGE AS INDEPENDENT VARIABLES AND WRITING SCORES AS DEPENDENT VARIABLE $(\mathrm{N}=168)$

\begin{tabular}{lllll}
\hline Steps & Procedures & Independent variables & $\mathbf{R}^{\mathbf{2}}$ & $\mathbf{R}^{2}$ changes \\
\hline $\mathbf{1}$ & Forced entry & Depth of vocabulary knowledge & $.417^{*}$ & $.453^{*}$ \\
\hline $\mathbf{2}$ & Forced entry & Breadth of vocabulary knowledge & $.036^{*}$ & \\
\hline
\end{tabular}

After comparing Table 8 and Table 3, we have found that depth of ESL learners' vocabulary knowledge can explain $42.3 \%$ of the change in their comprehensive language competence while breadth of vocabulary knowledge can only explain $39 \%$ of their overall language competence. Depth of vocabulary knowledge can make $10.4 \%$ more contributions to change in L2 learners' comprehensive language skills on the basis of their breadth of vocabulary knowledge, while breadth of L2 learner's vocabulary knowledge can only make $7.0 \%$ more contributions to their comprehensive language 
competence given their depth of vocabulary knowledge. The comparison of Table 9 and Table 5 shows that depth of vocabulary knowledge can explain $30.5 \%$ of the change in cloze scores while breadth of vocabulary knowledge can only explain 27.1\%; depth of vocabulary knowledge can make $8.0 \%$ more contributions to L2 learners' overall linguistic competence on the basis of their breadth of vocabulary knowledge while breadth of vocabulary knowledge can merely add $4.6 \%$ on the basis of depth of vocabulary knowledge. If we compare Table 10 and 7 , we can find that depth of L2 learners' vocabulary knowledge can explain $41.7 \%$ of change in L2 learners' writing scores while breadth of vocabulary knowledge can explain $31.9 \%$; depth of vocabulary knowledge can increase L2 learners' writing scores by $13.4 \%$ on the basis of their breadth of vocabulary knowledge while breadth of vocabulary knowledge can merely increase L2 learners' writing scores by 3.6\% on the basis of their depth of vocabulary knowledge.

In testing students' cloze and writing skills, the depth of their vocabulary knowledge is a better indicator of their comprehensive language competence, because cloze mainly tests learners' ability of using synonyms, collocations and discourse coherence. In this study tests on depth of L2 learners' vocabulary knowledge is about L2 learners' ability of using synonyms and collocations. At the same time, a large quantity of vocabulary does not guarantee high-quality writing and a good piece of writing requires students' to use words, collocations appropriately. Therefore, it is not enough for L2 learners to grasp the Chinese meaning of English words. They need to have higher depth of vocabulary knowledge which at least includes multiple explanations, synonyms and collocations of a new word.

Correlation analyses show that the correlation between breadth of vocabulary knowledge and reading $(r=.532)$ is higher than that between depth of vocabulary knowledge and reading $(\mathrm{e}=.471)$. On one hand, reading requires more of students' breadth of vocabulary knowledge than their depth of vocabulary knowledge. On the other hand, the target words used in this study are chosen from high-frequency words but the texts in reading tests contain vocabulary far beyond the level in the study and vocabulary tests in this study include academic vocabulary and some low-frequency but widely used academic words.

\section{B. Correlations between Breadth and Depth of Vocabulary Knowledge}

Before we explore the correlations between breadth and depth of L2 learners' vocabulary knowledge, it is necessary to divide all subjects into three groups according to their vocabulary and the standard of grouping is the mean \pm standard deviation formula, i.e. vocabulary test takers with scores below 61.57(77.33 - 15.76) fall into the low breadth group, those higher than $93.09(77.33+15.76)$ fall into the high breadth group and those in between fall into the medium breadth group. The sample number of each group is over 20, therefore we can conduct further statistical analyses with small samples. The correlations between breadth and depth of L2 learners' vocabulary knowledge with different vocabulary are listed in Table 11:

TABLE XI

CORRELATIONS BETWEEN BREADTH AND DEPTH OF L2 LEARNERS' VOCABULARY KNOWLEDGE WITH DIFFERENT VOCABULARY

\begin{tabular}{l|l}
\hline Variable & Depth of vocabulary knowledge \\
\hline Students with Low breadth of vocabulary knowledge & $.348 \pm$ \\
\hline Students with medium breadth of vocabulary knowledge & $.512^{* *}$ \\
\hline Students with high breadth of vocabulary knowledge & -.086 \\
\hline Total & $.649 * *$ \\
\hline
\end{tabular}

From table 11 we can see that in terms of total sample the breadth and depth of L2 learners' vocabulary knowledge are highly correlated(r>.05), which means that the increase in the breadth of L2 learners' vocabulary will promote the increase in the depth of their vocabulary knowledge. However, in the three small sample groups, the low breadth group has positive but insignificant correlation with the depth of their vocabulary knowledge while the high breadth group has negative correlation with the depth of their vocabulary knowledge. These results show that for some L2 learners the depth of their vocabulary knowledge did not grow with the increase of the breadth of their vocabulary knowledge. This is mainly because Chinese learners do not have very good learning and using English as a foreign language in China and for most non-English majors the main purpose of learning new words is to take tests and do reading exercises. Therefore many students devote most of their energy to rote memorization of word spelling and basic Chinese explanations but they ignore or do not realize the importance of learning the deep meaning of vocabulary; on the other hand, it is relatively easier for L2 learners to memorize and understand the breadth of vocabulary knowledge and it is much more challenging and time-consuming to grasp the depth of vocabulary knowledge. Therefore probably for the low breadth group, learning and memorizing word spelling and their basic Chinese explanations has used up their energy and they have no capacity or energy to consider the depth of their vocabulary knowledge.

\section{CONCLUSIONS}

The above statistical analyses show that both breadth and depth of L2 learner's vocabulary knowledge can predict effectively their comprehensive linguistic competence; the depth of L2 learners' vocabulary knowledge is better than breadth of vocabulary knowledge as an indicator of their comprehensive linguistic competence, which is reflected in cloze and writing tests. In general, the breadth of L2 learners' vocabulary knowledge is highly positively correlated with the depth of their vocabulary knowledge. 
According to the results of this study, we must admit that both the breadth and depth of L2 learners' vocabulary knowledge are significant and probably the depth of L2 learners' vocabulary knowledge is even more significant for two reasons: first of all, the synonyms and multiple meanings of words should be emphasized; secondly, the collocations of words should be stressed. Although the development of depth of L2 learners' vocabulary knowledge is generally consistent with the breadth of their vocabulary knowledge, for different language learners, the development of both aspects is very unbalanced. Advanced ESL learners should not only expand the breadth of their vocabulary but also pay attention to the development of their depth of vocabulary knowledge. Preliminary and intermediate learners should also increase the depth of their vocabulary knowledge apart from expanding the breadth of their vocabulary knowledge.

Due to time constraints and the limitations of test instruments, this study may not be comprehensive enough in terms of breadth of vocabulary knowledge and overall linguistic competence. Furthermore the subjects in this research are all second-year non-English majors which may not be representative enough of all ESL learners. Therefore the results of this study need to be supported and confirmed by further study in this field which is also the directions of our future studies.

\section{REFERENCES}

[1] Chappelle, C. (1998). Construct definition and validity inquiry in SLA research. In Bachman L. \& Cohen A. (eds.).Interfaces between Second Language Acquisition and Language Testing Research. Cambridge: Cambridge University Press. 32-70.

[2] Coxhead, A. (2000). A new academic word list. TESOL Quarterly 34.2, 213-238.

[3] Nation, I. (1983). Testing and teaching vocabulary. Guideline 5.1, 12-25.

[4] Nation, I. (1990).Teaching and Learning Vocabulary. New York: Newbury House Publishers.

[5] Qian, D. (2002). Investigating the relationship between vocabulary knowledge and academic reading performance: An assessment perspective. Language Learning 52.3, 513-536.

[6] Qian, D. (1999). Assessing the roles of depth and breadth of vocabulary knowledge in reading comprehension. The Canadian Modern Language Review 56.2, 283-307.

[7] Qian, D. \& M.Schedle.(2004). Evaluation of an in-depth vocabulary knowledge measure for assessing reading performance. Language Testing 21.1, 28-52.

[8] Read, J. (1995). Validating the Word Associates Formats as a measure of depth of vocabulary knowledge. Paper presented at the $17^{\text {th }}$ Language Testing Research Colloquium, Long Beach. CA.

[9] Schmitt, N. \& P. Meara. (1997). Researching vocabulary through a word knowledge framework: Word associations and verbal suffixes 1997.Studies in Second Language Acquisition 19.1, 17-36.

[10] Schmitt, N., D. Schmitt \& C. Clapham. (2001). Development and exploring the behavior of two new versions of the vocabulary levels test. Language Testing 18.1, 55-88

[11] Schmitt, N. \& M. McCarthy. (2002). Vocabulary: Description, Acquisition and Pedagogy. Shanghai: Shanghai Foreign Language Education Press.

[12] Wesche, M. \& T. Paribakht.S.(1996). Assessing second language vocabulary knowledge: Depth versus breadth. Canadian Modern Language Review 53.1, 13-40.

Zhaogang Wang was born in Shandong, China in 1974. He received his M.A. in Business English and PhD in economics at Dongbei University of Finance and Economics, Dalian, China in 2001 and in 2013 respectively. Given his interdisciplinary educational background, His research interests are also wide and interdisciplinary including language teaching, second language acquisition, language economics, and translation studies. 